(2)

\section{OPEN ACCESS}

Medical Ethics, Philosophy and History of Medicine, Erasmus MC, Rotterdam, The Netherlands

Correspondence to

Dr Pei-hua Huang, Medical Ethics, Philosophy and History

of Medicine, Erasmus MC, Rotterdam 3015 GD, The

Netherlands;

p.huang.1@erasmusmc.nl

Received 27 April 2021

Accepted 25 June 2021

Check for updates

(c) Author(s) (or their employer(s)) 2021. Re-use permitted under CC BY-NC. No commercial re-use. See rights and permissions. Published by BMJ.

To cite: Huang $P$.

$J$ Med Ethics Epub ahead of print: [please include Day

Month Year]. doi:10.1136/

medethics-2021-107545

\title{
COVID-19 vaccination and the right to take risks
}

Pei-hua Huang

\section{ABSTRACT}

The rare but severe cerebral venous thrombosis occurring in some AstraZeneca vaccine recipients has prompted some governments to suspend part of their COVID-19 vaccination programmes. Such suspensions have faced various challenges from both scientific and ethical angles. Most of the criticisms against such suspensions follow a consequentialist approach, arguing that the suspension will lead to more harm than benefits. In this paper, I propose a rights-based argument against the suspension of the vaccine rollouts amid this highly time-sensitive combat of COVID-19. I argue that by suspending a vaccine rollout, a government infringes people's right to take the risks they deem worth taking for their health. I also consider four potential objections to my argument and explain why none of them undermines my argument.

\section{INTRODUCTION}

The concern over the potential link between the AstraZeneca vaccine and cerebral venous thrombosis (CVT) has prompted several countries to suspend the use of the vaccine. For example, during the composition of this paper, Denmark announced plans to stop the rollout of the AstraZeneca vaccine permanently. ${ }^{1}$ In a recent interview, the head of the Dutch vaccination programme also stated that the AstraZeneca vaccine due to arrive in the Netherlands in mid-May will largely remain unused. ${ }^{2}$

Such decisions face various challenges from both scientific and ethical angles. First, there is a lack of sufficient scientific evidence. The investigation conducted by the European Medicine Agency (EMA) found no clear evidence that could confirm the link between the AstraZeneca vaccine and an increased risk of CVT. ${ }^{3}$ Second is the comparison between risks and benefits. By 9 March 2021, only 22 cases of thromboembolic events out of the 3 million people who received the AstraZeneca vaccine had been reported in the European Economic Area. ${ }^{4}$ Experts of the EMA concluded that even if the risk of CVT were confirmed, the health benefits of receiving the AstraZeneca vaccine would still significantly outweigh the risks. ${ }^{3}$ Suspending the vaccine rollout due to concerns about the extremely small risk of CVT is therefore likely to bring more harm than benefits to the general public's health. From a consequentialist's point of view, suspending the vaccine rollout is thus morally wrong.

The moral implications of the suspension go beyond a risk and benefit analysis. Given that largescale vaccination programmes only began in early 2021 , it is likely that new rare symptoms will be discovered as the number of inoculations grows. There's no risk-free option at the moment. It is puzzling that people are allowed to expose themselves to the risk of unknown symptoms caused by some vaccines, but not others. Such an arbitrary decision on which COVID-19-related risk people are allowed to take is morally unjustifiable and deeply problematic.

This paper offers a new angle on this debate, providing a rights-based argument against the vaccine suspension amid the highly time-sensitive battle against the COVID-19. I argue that by suspending the vaccine rollout, a government infringes a person's right to decide what risks they would like to take for their health. In the current situation where all available options bear health risks for various groups and to varying degrees, and the delay of vaccination can risk a person's life, depriving a person of the right to make their own medical decision fails to treat the person as a selfdetermined agent. Governments ought not to make such a decision on behalf of their people. Rather, they should assist them in making well-informed medical choices by communicating all the uncertainties and risks as clearly as possible.

\section{A RISK ANALYSIS}

Being vaccinated and remaining unvaccinated both involve risks. To undergo a vaccination, one has to undertake the risk of unwanted side effects and unexpected symptoms. This is partly the reason why, despite the imminent threat of COVID-19, compulsory COVID-19 vaccination programme remains highly controversial in most democratic countries. Given the number of unknowns about COVID-19 and about the available vaccines, making the vaccination programme compulsory would force people to take risks they might not be willing to take.

Remaining unvaccinated also exposes one to risks. The first quarter of 2021 saw a resurgence of the confirmed cases of COVID-19, with more than 10 million new cases reported to the WHO for the first 2 weeks of April 2021. ${ }^{5}$ The delay caused by vaccine rollout suspensions means that people are unable to take an immediate and statically effective action to reduce their risk of contracting COVID19. From this perspective, the suspension forces people to bear risks they do not want to bear.

In the current situation where COVID-19 continues to cause an enormous number of deaths each day, taking away people's opportunity to be vaccinated as soon as the vaccine is available forces them to continue to be exposed to risks of COVID19. This damages people's ability to act on their decisions regarding which risk they deem worth taking for their health.

This very simple risk analysis reveals an inconsistency between the decision made for the vaccine programme and the decision of suspension. Qua health risks, the risk of COVID-19 and the risk of CVT can both lead to fatal ramifications (some might even argue that the risk of COVID-19 is 
more concerning due to its infectious nature). If it is morally acceptable, or even desirable, to allow people to remain exposed to the risk of COVID-19, then it could also be morally acceptable, or even desirable, to allow people to expose themselves to the risk of CVT.

\section{THE RIGHT TO TAKE RISKS}

The problem we see here goes deeper than mere inconsistency. By this, I mean the issue would not be resolved if a government decided to make the vaccination programme compulsory such that it consistently interfered with people's health decisions. The fact that compulsory COVID-19 vaccination programme remains controversial suggests that that there is something more fundamental going on than consistency, that is, the importance of the right to take risks.

Take smoking as an example. We have had substantial evidence that smoking causes several health hazards, such as lung cancer, coronary heart disease and stroke. ${ }^{6}$ In the USA alone, smoking causes more than 480000 deaths each year. ${ }^{7}$ Putting this figure into context, we can see the health risks brought about by smoking are not negligible-by 23 April 2021, the statistics gathered by the US Centers for Disease Control and Prevention reported 566494 deaths from the COVID-19. ${ }^{8}$ However, most countries do not impose a categorical ban on tobacco usage, but restrictions on smoking indoors (eg, workplaces, hospitals, schools and libraries).

The rationale behind the (limited) regulations of smoking can be understood with John Stuart Mill's Harm Principle. According to the Harm Principle, the only occasion where a government can rightly exercise its power over any member of society, against their will, is to prevent harm to others. ${ }^{9}$ In the case of smoking, if a smoker is only to increase their own health risks via smoking, they are entitled to do so. Yet, because smoking indoors will cause health hazards to others against their will, it is justifiable to restrict the smoker's freedom to smoke by prohibiting indoor smoking.

It is intriguing to see that smoking remains legal, even though it brings no clear health benefits but brings a myriad of health hazards, while certain vaccines are suspended, even if the health risks are small and the benefits are enormous. Or, to put it more precisely, it is morally problematic that people are allowed to risk their health by smoking but not allowed to take on a small risk of CVT for the sake of their health and that of the people around them. The ethical foundation of suspending the vaccine rollout is shaky once we compare the decision with other healthrelated policies. So long as the risk of harm is limited to the person, the government shall not intervene in the person's decision. The right to take risks one deems worth taking should be respected.

My argument for the right to take risks is based on the liberal tradition in political philosophy, an approach that is sometimes criticised as overly individualistic and lacking in consideration of values such as solidarity. I agree that this approach has its limitation, and values like solidarity are usually not its primary consideration. Nonetheless, the risks involved in this context make the discussion of the right to take risks very different from cases like smoking. Indeed, unlike with smoking, solidarity can be seen in the act of choosing to take on the risk.

One of the major reasons for the suspension of the vaccine developed by AstraZeneca is that the younger population faces a lower risk of dying from COVID-19, and therefore it is seen as undesirable to expose the younger population to the risk of CVT. ${ }^{\mathrm{i}}$ The reasoning running here is that, for a person, if receiving a vaccination would bring them undue (although very small) health risks, then the person ought not to be given the vaccination. It does not consider the possibility that some people might be more than willing to take on this risk for the sake of solidarity. A person with a low risk of developing severe COVID-19 symptoms might deem the risk of CVT worth taking because they are convinced that taking this risk for the sake of herd immunity is worthwhile.

It is important to note that the coronavirus has mutated and can mutate further. We have no means to predict when it will mutate further and whether the vaccines we have now will be as effective against new variants. For instance, there is some evidence suggesting that Pfizer's vaccine is less effective against the South African variant, for instance. ${ }^{11}$ Due to this risk, it is not unreasonable for one to think that taking on a small risk of CVT in exchange for reaching herd immunity as soon as possible is a moral imperative. By suspending the vaccine rollout, a government deprives people both of the right to determine what risks one is willing to undertake, and of the opportunity to act on one's call of moral duty to protect one's society from its people.

\section{OBJECTION I: DUTY TO PROTECT}

A potential reply to my argument is that the government has a duty to protect its people from undue health risks, and therefore suspending the vaccine rollout is justifiable. The ideal of the Harm Principle is seldom closely followed. Most jurisdictions try to balance the trade-offs between respecting people's right to take risks and implementing paternalistic regulations. The seatbelt requirement is an example. The requirement is motivated by protecting the lives of drivers and passengers, not by preventing harm to others. A paternalistic intervention from the government can be justifiable, if the cost of the intervention is minimal and the benefit significant.

Under ordinary circumstances, this argument is well founded and reasonable. However, the COVID-19 context we are considering here renders the talk of duty to protect self-defeated. To protect a person means to shield the person from potential harms, or at least, to reduce the likelihood of being harmed. A study conducted by the research team at the University of Oxford showed that the risk of developing CVT from the AstraZeneca vaccine (5 per million people) is only slightly higher than the risk of developing CVT after receiving the Moderna vaccine or the Pfizer vaccine (4.1 per million people). This study also showed that the risk of developing CVT from the COVID-19 (39 per million) is roughly eight times higher than the risk of developing CVT from the AstraZeneca vaccine. ${ }^{12}$ Attempts to use the duty to protect to justify the suspension of the rollout overlook the fact that the suspension might expose people to greater risk of CVT.

Furthermore, research conducted by the EMA also found that the risk of COVID-19 is far greater than the risk of CVT. ${ }^{3}$ The suspension means that people who prefer the less risky option (ie, to receive a vaccination that involves a small risk of CVT to reduce the risk of COVID-19) are forced to keep to the more risky option (ie, to remain unvaccinated and expose to the risk of COVID-19). An intervention that forces a person to remain exposed to greater health risk is not protecting the person.

${ }^{\mathrm{i}} \mathrm{Cf}$. the statistics gathered by Centres for Disease Control and Prevention. ${ }^{10}$ 


\section{OBJECTION II: PUBLIC CONFIDENCE AND VACCINE HESITANCY}

One might acknowledge that side effects linked to the AstraZeneca vaccine are less than the risks of not inoculating, yet insist that continuing the rollout of AstraZeneca might reduce public confidence in vaccination. Thus the risk-benefit analysis ought to include indirect harms like illness and deaths caused by vaccine hesitancy and take into consideration steps that might mitigate vaccine hesitancy. On this framing, suspending the vaccine rollout gestures that the government is taking all the necessary steps to safeguard its people from undue risks.

Indeed, suspension of vaccination could bring about positive effects like restoring or strengthening the general public's trust in vaccination. However, in reality, the suspensions did not achieve these goals. Rather, they created confusion and widespread hesitancy. A recent survey funded by European Union found that vaccine hesitancy rose in European countries by $9 \%$ after the several countries decided to suspend the use of the AstraZeneca vaccine. $^{13}$

A better way to tackle the problem of vaccine hesitancy is clear communication. Clinical research is not always easy to comprehend. It is especially difficult when we are dealing with risks in a highly uncertain situation where we do not have a good reference point to help us determine if a risk is worth taking. It is understandable that some people became hesitant after they learnt about the CVT side effects. However, paternalistically suspending the rollout of the AstraZeneca vaccine does not offer any meaningful clarification. Rather, it further fuels vaccine hesitancy.

\section{OBJECTION III: ARGUMENT OF ALTERNATIVES}

Another potential objection to my argument may rely on the idea of alternatives. One may argue that suspending the rollout of vaccines that increase the risk of CVT is morally justifiable because there are other vaccines that are less suspected of this risk. This is indeed the argument given by the head of Dutch vaccination programme.

This argument would be reasonable if it were not for the timesensitive aspect of the COVID-19 context. When certain governments decided to suspend part of their vaccine programmes due to the concerns of CVT risk, there was no sign of an end of the pandemic, and no ability to immediately fill the gap with other vaccines. The delay caused by the disruption impairs people's ability to take an immediate action they otherwise could have taken to reduce their risk of contracting COVID-19 and/or helping their community reach herd immunity as quickly as possible. In a time-sensitive situation such as the one we are in, options that cannot be accessed by people in a timely manner cannot qualify as a reasonable alternative.

\section{OBJECTION IV: CAUSING HARM AND LETTING NATURE TAKE ITS COURSE}

The final objection I consider here focuses on the difference between actively causing harm to a person and passively letting a person be exposed to harm. One might argue that my argument fails to recognise that from the government's point of view, there's a fundamental difference between the harm caused by vaccination and by COVID-19. The upshot of this objection focuses on the involvement of human agency. Given that we have known that certain vaccines seem to cause CVT, inoculation is akin to intentionally and actively causing harm to the vaccine recipients. In contrast, while the suspension might let some become infected by the COVID-19, since nobody actively causes the infection, we should see these cases as unfortunate incidents.

This objection shares much similarity with the arguments presented in the literature on euthanasia on whether there is any moral significance between letting die and killing. ${ }^{14}{ }^{15}$ Indeed, the involvement of human agency may be morally relevant in certain cases. Yet, whether this perspective is helpful in differentiating the risk of CVT from the risk of contracting COVID-19 is another matter. By suspending the vaccine rollout, the government actively decides to expose people to risks of COVID-19 they could otherwise avoid. It is fallacious to think that letting nature take its course is morally less concerning than directly causing harm in this context. Nature cannot take its course unless there is human omission. In this context, inaction is also an action.

\section{CONCLUSION}

Suspending the rollout of vaccines that are suspected of increasing the risk of CVT is well-intentioned. Under ordinary circumstances, it is desirable to see the government taking cautious measures to safeguard its people's health. However, we are currently in an unusual situation where no one knows for sure which counter-COVID-19 measures will prove the most effective, and all of the available options involve different risks. It is puzzling that people are allowed to take on the risk of contracting COVID-19 by turning down the opportunity to be inoculated, while there is no such an option for accepting a slightly increased risk of CVT in exchange for shielding oneself from the risks of COVID-19.

The government ought not to make such life-and-death decisions for its people. Instead, it should acknowledge the uncertainties, explain the known risks and benefits of each currently available option, and assist people in making a well-informed and autonomous medical decision. Depriving people of their right to determine what risks they are willing to take and forcing them to remain exposed to a greater risk is morally unacceptable.

Correction notice This paper has been revised to correct references 3, 4,6 and 9 . Twitter Pei-hua Huang @Peihua_Huang

Acknowledgements I thank Nick Binney, Hafez Ismaili M'hamdi, and Charlotte Bomhof for the thought-provoking discussion we had on the ethics of COVID-19 vaccination. I also thank Suzzane van de Vathorst, Maartje Schermer and the anonymous reviewers of the journal for giving me constructive feedback during the composition of this paper. I would also like to give special thanks to Lucy Valenta and Andrew McLoughlin for going through the revision with me.

Contributors $\mathrm{PH}$ is the sole author of this paper.

Funding This research is suppoprted by the Convergence for health and technology initiative of Erasmus MC and TU Delft.

Competing interests None declared.

Patient consent for publication Not required.

Provenance and peer review Not commissioned; externally peer reviewed.

Data availability statement There are no data in this work.

Open access This is an open access article distributed in accordance with the Creative Commons Attribution Non Commercial (CC BY-NC 4.0) license, which permits others to distribute, remix, adapt, build upon this work non-commercially, and license their derivative works on different terms, provided the original work is properly cited, appropriate credit is given, any changes made indicated, and the use is non-commercial. See: http://creativecommons.org/licenses/by-nc/4.0/.

\section{ORCID iD}

Pei-hua Huang http://orcid.org/0000-0001-5334-8615 


\section{REFERENCES}

1 BBC. AstraZeneca vaccine: Denmark stops rollout completely, 2021. Available: https:// www.bbc.com/news/world-europe-56744474

2 ven Dongen A, van Mersbergen C. RIVM-vaccinatiebaas: 'Miljoenen doses AstraZeneca die na half mei komen, zijn niet meer nodig'. Algemeen Dagblad 2021.

3 European Medicines Agency. COVID-19 vaccine AstraZeneca: benefits still outweigh the risks despite possible link to rare blood clots with low blood platelets, 2021. Available: https://www.ema.europa.eu/en/news/covid-19-vaccine-astrazenecabenefits-still-outweigh-risks-despite-possible-link-rare-blood-clots

4 European Medicines Agency. COVID-19 vaccine AstraZeneca: PRAC preliminary view suggests no specific issue with batch used in Austria, 2021. Available: https:// www.ema.europa.eu/en/news/covid-19-vaccine-astrazeneca-prac-preliminary-viewsuggests-no-specific-issue-batch-used-austria

5 World Health Organization. Who coronavirus (Covid-19) Dashboard, 2021. Available: https://covid19.who.int/ [Accessed 26 Apr 2021].

6 National Health Service. What are the health risks of smoking? 2018. Available: https://www.nhs.uk/common-health-questions/lifestyle/what-are-the-health-risks-ofsmoking/
7 U.S. Department of Health and Human Services. The health consequences of Smoking - 50 years of progress: a report of the surgeon General. Atlanta, US, 2014

8 U.S. Centers for Disease Control and Prevention. United States Covid-19 cases and deaths by state, 2021. Available: https://covid.cdc.gov/covid-data-tracker/\#cases_ totaldeaths [Accessed 7 Jun 2021].

9 Mill JS. Utilitarianism and On Liberty. 2. UK: Blackwell Publishing, 2003.

10 Centers for Disease Control and Prevention. Centers for Disease Control and Prevention. Risk for COVID-19 Infection, Hospitalization, and Death By Age, 2021 Available: https://www.cdc.gov/coronavirus/2019-ncov/covid-data/investigationsdiscovery/hospitalization-death-by-age.html

11 Kustin T, Harel N, Finkel U, et al. Evidence for increased breakthrough rates of SARS CoV-2 variants of concern in BNT162b2-mRNA-vaccinated individuals. Nat Med 2021. doi:10.1038/s41591-021-01413-7. [Epub ahead of print: 14 Jun 2021].

12 Taquet M, Husain M, Geddes JR. Cerebral venous thrombosis: a retrospective cohort study of 513,284 confirmed COVID-19 cases and a comparison with 489,871 people receiving a COVID-19 mRNA vaccine, 2021. Available: https://osf.io/a9jdq/

13 Ahrendt D, Mascherini M, Nivakoski S. Living, working and COVID-19 2021.

14 McLachlan HV. The ethics of killing and Letting die: active and passive euthanasia. $J$ Med Ethics 2008;34(8):636-8.

15 Singer P. Practical ethics. 2nd ed. Cambridge: Cambridge university press, 1993. 